\title{
Otto Büchler E Seus Livros De Matemática: Vetores De Transferência Cultural
}

\section{Otto Büchler And His Textbooks Of Mathematics: Vectors Of Cultural Transference}

\author{
Circe Mary Silva da Silva * \\ Universidade Federal de Pelotas - UFPel
}

\begin{abstract}
Resumo
Este artigo pretende discutir a circulação dos escritos de Otto Büchler para o ensino de matemática, bem como a transferência de saberes que a circulação desses escritos significou, no início do século $\mathrm{XX}$, no Brasil. Mediante análise de conteúdo de fontes primárias e tendo como referencial as transferências culturais (conforme Espagne), buscamos responder a seguinte questão investigativa: que proposta de ensino de matemática é possível identificar nos registros escritos de Otto Büchler? Otto Büchler foi um agente cultural germânico que fez circular, por meio dos livros didáticos editados no Brasil e artigos publicados na revista pedagógica intitulada Jornal Geral do Professor para o Rio Grande do Sul (AZL), ideias sobre o ensino da matemática oriundas da Europa. Deixou entrever nesses textos princípios do método intuitivo e indícios de Escolanovismo sobre o ensino da matemática. Ali ele notadamente defende um ensino que instigue o pensamento e promova ações que favoreçam a descoberta de conceitos e a obtenção de resultados pelo aluno.
\end{abstract}

Palavras-chave: Otto Büchler; ensino da matemática; transferências culturais.

\begin{abstract}
This article intends to discuss the circulation of Otto Büchler's writings for the teaching of mathematics, as well as the transfer of knowledge that the circulation of these writings meant, in the early twentieth century, in Brazil. By analyzing content from primary sources and taking as reference the cultural transfers (according to Espagne), we seek to answer the following research question: what kind of mathematics teaching can be identified in the written records of Otto Büchler? Otto Büchler was a German cultural agent who circulated, through the textbooks edited in Brazil and published articles, ideas on the teaching of mathematics from Europe in the pedagogical journal titled Jornal Geral do Professor para o Rio Grande do Sul (ALZ) (General Journal of the Teacher for the state of Rio Grande do Sul). He left in these texts principles of the intuitive method and signs of new teaching alternatives on the teaching of mathematics. There he notably defends a teaching that instigates thought and promotes actions that favor the discovery of concepts and the achievement of results by the student.
\end{abstract}

Keywords: Otto Büchler; mathematics teaching; cultural transfers.

\footnotetext{
* Doutora em Pedagogia pela Universidade de Bielefeld (Alemanha). Professora e pesquisadora visitante do CNPq no Mestrado em Educação Matemática da UFPel. E-mail: cmdynnikov@gmail.com
} 


\section{Preâmbulo e Caminho Investigativo}

O termo transferência cultural marca a preocupação de falar simultaneamente de vários espaços nacionais, de seus elementos comuns, sem justaposição das considerações sobre um e outro para confrontá-los, compará-los ou simplesmente acumulá-los (Espagne, 1999, p. 1).

Investigadores como Espagne (1999), Dittricht (2013) e Fontaine (2014), entre outros, utilizam as transferências culturais para entender as interações entre culturas e sociedades numa dinâmica histórica. Fontaine toma os três seguintes aspectos de transferência para estudo: 1) as motivações e interesses que levam um contexto cultural a importar um conhecimento modelado em outro contexto; 2) o processo de mediação conduzido pelos agentes que permitem a transferência do saber cobiçado; 3) a transformação semântica que acompanha o processo de transferência. O presente estudo toma como foco de análise o autor Otto Büchler, agente cultural e autor de livros didáticos de matemática, atributos que, segundo Espagne, são vetores de transferência cultural.

Fontaine (2014) analisou o processo pelo qual métodos e práticas de ensino ultrapassaram fronteiras por meio de mediadores em contextos locais específicos. A análise do papel de agentes culturais como Otto Büchler insere-se nessa vertente.

No contexto das comunidades teuto-brasileiras no Rio Grande do Sul, emergiu a necessidade de construir um sistema educacional para atender os filhos de imigrantes. Os imigrantes alemães, vivendo, muitas vezes, isolados nas colônias do meio rural e sem domínio da língua portuguesa, conservaram a língua materna e continuaram, em sua maioria, sem domínio da língua do país que os acolheu (Silva, 2016). Nesse sentido, a importação de ideias da metrópole - Alemanha - era entendida como algo "natural" e por isso à época não deve ter provocado muitos questionamentos. Tomando o primeiro aspecto de transferência apontado por Fontaine, constata-se que havia motivações suficientes para "importar" um conhecimento modelado no além-mar uma vez que o governo brasileiro não apresentava, segundo a opinião dos imigrantes alemães, alternativas de acesso à educação nessas comunidades. Acrescente-se a isso que o Brasil não possuía à época uma tradição educacional que pudesse ser comparada a da Alemanha. Para Bastos (2000, p. 106), que analisou as apropriações das ideias pedagógicas francesas, especialmente de Buisson, por líderes intelectuais brasileiros como Rui Barbosa, “a apropriação dessas ideias deve ser também compreendida na perspectiva de transferência de conhecimentos ou de um saber fazer, dentro de uma hierarquia de estado de desenvolvimento de um país para outro". 
Nas escolas étnicas do Rio Grande do Sul, inexistiam, assim como na Alemanha, imposições aos professores sobre a adoção de livros. Entretanto, nos periódicos ${ }^{1}$ que circulavam entre os professores destas escolas, estava presente um discurso favorável à adoção do livro didático ou, pelo menos, de seu uso pelo professor como um manual ou roteiro de aula (Arendt, 2008). Os periódicos educacionais, que surgiram a partir de 1900 por iniciativa das associações de professores católicos e evangélicos, serviram para direcionar as leituras que os professores deveriam fazer bem como os livros didáticos a consultar ou adotar. Dialogando com Bourdieu (2007), identificamos nos periódicos dedicados aos professores das escolas étnicas um campo de produção erudita que buscava ele próprio ditar as normas de produção e avaliação de seus produtos, quase como que legitimando essa produção a partir de seus próprios pares: “[...] obedece a lei fundamental da concorrência pelo reconhecimento propriamente cultural concedido pelo grupo de pares que são, ao mesmo tempo, clientes privilegiados e concorrentes" (Bourdieu, 2007, p. 105). Resenhas de comentadores sobre as obras didáticas eram comuns nos periódicos escritos em língua alemã, bem como artigos produzidos pelos próprios autores dessas obras. Além disso, tais periódicos veiculavam sistematicamente massiva propaganda das editoras, objetivando a venda dos livros didáticos. Esse arsenal, claro está, não era neutro: tinha o propósito de inculcar no professor quais os autores alemães a serem lidos, como também de fomentar a preservação e o fortalecimento da germanidade. Para Seyferth (1982), a germanidade constitui-se de elementos como herança sanguínea e a língua alemã. Além dessas dimensões, a germanidade envolve a herança cultural.

Foi nas páginas desses periódicos educacionais que despontou o nome de um autor de livros de matemática - Otto Büchler. Pesquisadores como Kreutz (1994); Hoff (2003); Gaertner (2004; 2016); Mauro (2005), Arendt (2008), Eissler \& Pinto (2013); Kuhn \& Bayer (2016; 2017) têm feito referência aos livros didáticos de matemática de Otto Büchler e também analisado sua obra desde diferentes perspectivas, destacando a repercussão que ela teve nas primeiras décadas do século XX, principalmente nas escolas teuto-brasileiras, e o sucesso editorial que alcançou.

Para Kreutz (1994) a Arithmetica Prática em quatro partes, de autoria de Otto Büchler, merece destaque por ter alcançado mais de dez edições, tendo sido vendidos mais de 160 mil

\footnotetext{
1 Circularam três importantes periódicos educacionais nas comunidades alemãs - para os evangélicos: Allegemeine Lehrerzeitung (ALZ) e Das Schulbuch (DASCH) e para os católicos: Mitteilungen des Katholischen Lehrer - und Erziehungsvereins der Deutschen Einwanderung in RS.
} 
exemplares. Segundo a investigação de Mauro (2004), a documentação de 1929 comprova a utilização da Arithmetica de Büchler pela maioria das escolas alemãs no Rio Grande do Sul e, também, no Estado de Santa Catarina. Gaertner confirma a utilização de tais livros em Santa Catarina (Gaertner, 2004). Se os livros didáticos desse autor alemão tiveram tão ampla circulação nas escolas, possivelmente, possuíam uma proposta pedagógica bem definida e interessante. Diante disto nos colocamos a seguinte pergunta: que proposta de ensino de matemática é possível identificar nos registros escritos de Otto Büchler?

Otto Büchler editou esses livros na época em que atuava como docente no Seminário Evangélico Alemão de Formação de Professores em Santa Cruz (RS), o qual, abreviadamente, identificamos como DELS. Os seminários de formação de professores têm história antiga nos estados que deram origem à Alemanha. Em 1903, havia 133 seminários de formação de professores primários na Prússia, desses, 85 eram de confissão religiosa evangélica, 44 católicos e 4 eram mistos (Lexis, 1904). Até o início do século XIX, nos estabelecimentos de formação de professores, a matemática ensinada restringia-se, principalmente, aos conteúdos da escola primária. Segundo Lexis (1904), começa no século XIX um aprofundamento dos conteúdos de matemática e, no início século do XX, uma formação mais especializada, o equivalente ao ministrado em um ginásio alemão (ensino secundário). No início do século $\mathrm{XX}$, as disciplinas científicas ministradas nos seminários dividiam-se em: Humanidades (Pedagogia, Psicologia, Religião, Língua materna, Língua estrangeira, História); Científicas (Aritmética, Ciências naturais, Geografia); Artísticas (Arte, Desenho, Música, Ginástica e Canto) e de Preparação para o ensino (treinamento para o ensino). Essa orientação foi mantida no DELS.

Para a presente investigação, lançamos mão de uma análise documental que contemplou, principalmente, os livros didáticos do autor, artigos por ele escritos no jornal Allegemeine Lehrerzeitung (ALZ) e artigos sobre seus livros publicados no periódico Das Schulbuch $(D A S C H)^{2}$. Os artigos de Büchler do ALZ ainda não foram objeto de análise pelos pesquisadores que se dedicaram ao estudo de sua obra, entre eles, Mauro (2005). Além disso, pouco se conhece sobre a vida de Otto Büchler. As várias tentativas realizadas para encontrar alguma pista sobre sua vida fracassaram. Pesquisamos nos jornais periódicos da época (início do século XX), já que então era prática comum publicar os nomes dos imigrantes chegados ao

\footnotetext{
2 Das Schulbuch (O livro escolar) teve sua primeira edição em 1917. Era um periódico mensal destinado ao fomento de uma literatura de livros escolares no Brasil e direcionado em primeira instância aos professor e demais interessados. Circulou até 1938, embora tenha tido uma interrupção de sete anos na publicação.
} 
Brasil, e neles nada encontramos. Consultamos os arquivos do Projeto Imigrantes (www.projetoimigrantes.com.br), onde localizamos registros de imigrantes com nomes semelhantes ao de Otto Büchler, mas não o dele. O Museu Histórico Visconde de São Leopoldo, que possui acervo considerável sobre os imigrantes alemães, também não tem registro sobre Otto Büchler. Restou-nos, então, fazer uma tentativa indireta de descobrir pistas nos periódicos AZL e DASCH e nos relatórios de diretores do DELS.

\section{Otto Büchler em Santa Cruz}

Não foi possível determinar, com exatidão, a data da chegada de Otto Büchler, em Santa Cruz. A primeira referência ao seu nome aparece no Relatório do Diretor do DELS de 1912, quando este teria substituído o professor Liersche nas disciplinas pedagógicas a partir de agosto daquele ano ( $3^{\circ}$ Jahresbericht des Deutschen Evangelischen Lehrerseminars für Rio Grande do Sul in Brasilien, 1912, p. 4). Mas é possível que ele tenha ingressado no Brasil anteriormente a essa data $^{3}$ e tenha atuado na docência antes de o diretor citá-lo como professor do DELS. Em 1913, ele era o professor de Psicologia, com duas horas semanais, e de Metodologia também, com a mesma carga horária. Juntamente com o diretor Vogel, ele ministrava as aulas de prática de ensino. Mas a primeira aparição de seu nome no AZL ocorreu em abril de 1913, quando consta como professor da Escola Sinodal e como membro contribuinte da Associação de Professores Evangélicos. Em 1914, integra a comissão de exames finais, junto com o pastor Kreuzer, de Lageado; o pastor Dohms, de Cachoeira, e o Diretor do Seminário. No dia 10 de dezembro, foi o examinador das provas orais de Matemática assim como das provas práticas de Pedagogia, Música e Ginástica.

Sobre sua formação temos, apenas, alguns indícios obtidos a partir do prefácio da $1^{\mathrm{a}}$ edição do livro Praktische Rechenschule in vier Heften für Deutschen Schulen in Brasilien (Aritmética Prática em quatro partes para as escolas alemãs no Brasil). Nele, escreveu: “O autor, aluno do egrégio matemático e professor de Metodologia da Aritmética A. Büttner ${ }^{4}$, fez empenho em publicar um livro verdadeiramente prático" (Büchler, 1915, p. 4). Por essa declaração, há fortes indícios de que Otto Büchler tenha frequentado um Seminário de Formação de Professores na Alemanha, já que em tais instituições havia a oferta de disciplinas

\footnotetext{
${ }^{3}$ Há notícia de ingresso de um alemão - Otto Büchler - no Rio de Janeiro com destino a Porto Alegre, em 25 de março de 1899 (Jornal do Comercio, 25/03/1899). Não temos confirmação de que se trata da mesma pessoa.

${ }^{4}$ Adolf Büttner (1827-1907), de origem alemã, foi professor e autor de muitos livros de matemática.
} 
como a referida Metodologia da Aritmética. Outro indício que o autor nos fornece foi encontrado na seguinte afirmação: "Esta pequena obra é o resultado de mais de 20 anos de prática no ensino de aritmética, ainda, obtida nas escolas estrangeiras e acompanha os progressos da metodologia da aritmética feitos no tempo moderno até o ano corrente e adaptados às nossas escolas" (Büchler, 1915, p. 4). Essas são pistas que nos levam a afirmar que ele recebeu sua formação num Seminário de Formação de Professores, pois, em caso contrário, dificilmente o diretor do DELS permitiria que ele ministrasse a disciplina de Psicologia. Isso porque, na Alemanha, a docência de tal disciplina era, em geral, prerrogativa do diretor, que era quem detinha sólida formação em Pedagogia, além de centralizar o poder no Seminário.

Büchler enalteceu o papel do mestre Büttner em sua formação, atribuiu importância às suas experiências como professor e demonstrou interesse pelas questões referentes a uma metodologia da aritmética, consciente de que ela não era, nem poderia ser estática, pelo contrário, estava sujeita a constantes modernizações, e daí a necessidade de adaptá-la para o contexto do Brasil.

O livro de Büttner foi sugerido como leitura básica para os seminaristas pelo diretor Strothmann. Ele aparece numa relação de 12 autores que deveriam ser lidos no DELS Anleitung für den Rechnen und Raumlehre-Unterricht, entre os quais está incluído Pestalozzi (ALZ, 1923, n. 1, p. 8-9).

\section{Os livros didáticos de matemática de Otto Büchler}

O olhar lançado aos livros didáticos de Büchler, escritos há cem anos, não pode ser o de um leitor do século XXI, que convive com uma realidade de autores de outro mundo editorial. É preciso lembrar o que Certeau (1982, p. 33) nos ensinou: “[...] uma leitura do passado, por mais controlada que seja pela análise dos documentos, é sempre dirigida por uma leitura do presente". O investigador se vê impelido a buscar novos significados para "velhas" afirmações contidas em tais materialidades. Há séculos lutas e embates para a produção de livros escolares giravam em torno de outros valores e interesses. No caso dos livros de Büchler editados pela Livraria Rotermund, eles surgiram para suprir a falta de livros destinados ao ensino da matemática, específicos para a comunidade de fala alemã.

O surgimento de uma instituição de formação de professores para as escolas evangélicas alemãs, a profissionalização de docentes para o magistério primário e a proliferação de 
escolas rurais do RS, em 1938 havia 500 escolas evangélicas no RS, (Naumann, 1978), geraram novas necessidades - uma delas, a de livros didáticos para os diferentes saberes que integravam o currículo do ensino elementar, principalmente: língua e matemática.

O primeiro livro intitulado Aritmética Prática em 4 partes para as escolas alemãs no Brasil [Praktische Rechenschule in vier Heften für Deutschen Schulen in Brasilien] começou a ser anunciado em fins de 1914. No ALZ, aparece em dezembro de 1914 uma propaganda da editora Rotermund (Figura 1), já incluindo o livro de Büchler, a ser lançado.

Até 1915, esta editora não havia publicado nenhuma obra nessa área. Mas sua concorrente - a Selbach - havia editado os livros de Friedrich Bieri (a primeira edição ocorreu em 1873) e de Kleikamp, cujas propagandas começaram a aparecer no AZL a partir de 1912 (Silva, 2015). Naturalmente, a Editora Rotermund tinha interesse em comercializar um livro de matemática uma vez que, assim, aumentaria o seu rol de livros didáticos, antes voltado para as disciplinas de alemão, português e religião.

Os livros de Büchler receberam massiva propaganda no ALZ, tanto por parte do editor do jornal, quanto da editora Rotermund que, mensalmente, incluía anúncio de seus livros didáticos, com resenhas muito positivas.

Por vários anos, apareceram no ALZ propagandas como a da figura 1, em que os títulos, autores e preços dos livros mostram as possibilidades de livros para os professores.

No jornal $A$ Federação ${ }^{5}$ do período não encontramos nenhum anúncio dos livros de Otto Büchler, o que nos leva a presumir que o ALZ era o veículo dominante de propaganda de tais livros. Em 1916, no ALZ, a segunda edição dos quatro volumes era saudada como um grande sucesso de vendas. Em 1933, surgiu a $13^{\mathrm{a}}$ edição do volume 1 e a $12^{\mathrm{a}}$ edição do $2^{\mathrm{o}}$ volume.

\footnotetext{
${ }^{5}$ A Federação, jornal que circulou amplamente de 1884 a 1937 em Porto Alegre, era do partido republicano.
} 


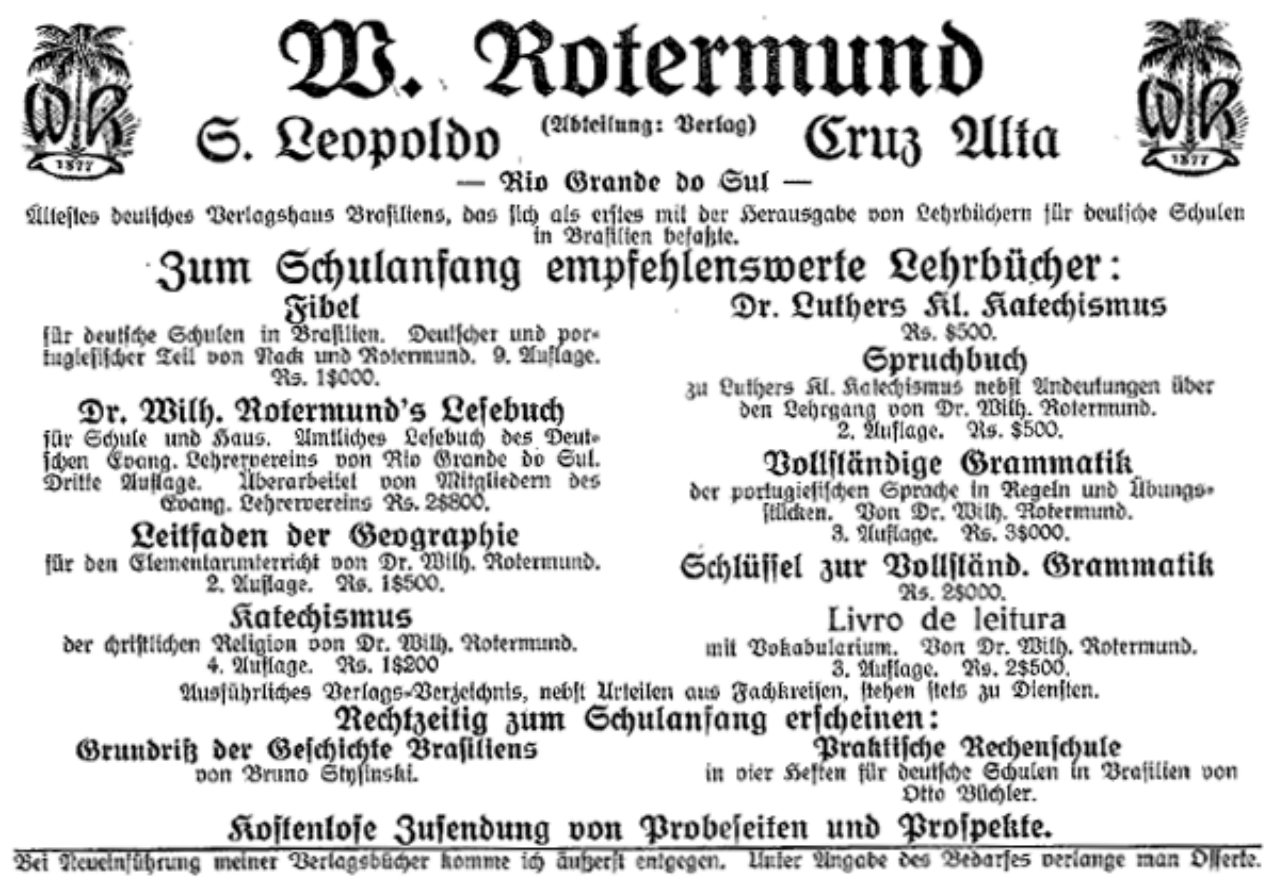

Figura 1: Propaganda de livros da editora Rotermund no ALZ, dezembro 1914 Fonte: ALZ, dez, 1914, p. 7

No ALZ encontram-se espaços destinados, exclusivamente, aos livros: Livros recebidos [Eingegangene Bücher]; Resenha de livros [Buchbesprechungen]; Mesa de livros [Büchertisch] e Livros novos [Neue Bücher], o que indica a importância a eles atribuída. Segundo Arendt (2008, p. 232), em praticamente todos os números do ALZ após 1920, esses espaços são encontrados: "Nas décadas de 1920 e 1930, encontramos respectivamente 161 e 88 obras indicadas e/ou resenhadas". A resenha de abril de 1915, no ALZ, enaltece o tipo de impressão, provavelmente pouco comum em livros didáticos, com uso de duas cores (preto e vermelho). Considera ser muito eficaz a utilização das duas cores para uma melhor visualização das lições.

Entretanto, em 1918 já aparece a edição em língua portuguesa desse mesmo livro, feita por Homero Dias Cardoso ${ }^{6}$ (Mauro, 2005, p. 91), formando da primeira turma do DELS. Edições nas duas línguas: alemão e português coexistiram por vários anos. Cabe aqui uma pergunta: Por que a editora Rotermund resolveu lançar a mesma obra em língua portuguesa, numa época em que, ainda, não havia proibição do uso do idioma alemão nas escolas? A

\footnotetext{
${ }^{6}$ Homero Dias Cardozo, formado em 1913, atuou como professor na Escola Alemã Evangélica da Associação Escolar, de Sapiranga, nas décadas de 1920 e 1930. Essa instituição teve variadas denominações e atualmente é o Instituto Sinodal Duque de Caxias. Informações disponíveis $\mathrm{em}$ http://www.al.rs.gov.br/taquigrafia2003/transcricoes/sessoesplenarias/50/2000/001129.htm.
} 
primeira hipótese que formulamos foi a comercial. Como o Praktische Rechenschule e a Taboada Primária para os principiantes alcançaram muita aceitação nas escolas, a Editora Rotermund aproveitou esse filão comercial para ampliar o seu acervo que, até então, era formado, primordialmente, por livros escritos em língua alemã e destinados às escolas teutobrasileiras. Mas essa hipótese, talvez, seja ainda muito simplista, se tivermos em conta o que diz um artigo de Strothmann, de 1923, sobre os livros de Büchler:

Era de se esperar que os dois livros iriam encontrar uma recepção calorosa nas escolas do idioma do país. O método alemão no ensino de aritmética é o melhor construído em todo o mundo e os dois livros, que se apresentam em versão portuguesa irão despertar o respeito, sem dúvida, da maneira alemã de ensino. Ou seja, a Aritmética Practica que compreende as 4 operações aritméticas básicas com números 1-100, foi traduzida do alemão para o português pelo professor $\mathrm{H}$. Cardozo, formado no Seminário Evangélico de formação de professores do Rio Grande do Sul, de modo que o sucesso da montagem correta e a simplicidade linguística das tarefas permaneceu como na original (ALZ, 1923, nov, p. 10, tradução livre da autora).

Remetendo-nos a Foucault (2004, p. 10), para quem o discurso não é neutro e não é apenas aquilo que traduz as lutas de dominação, mas representa o "poder do qual nos queremos apoderar", encontramos no texto de Strohtmann, diretor do DELS e editor da ALZ, portanto, alguém que detém poder, um discurso em que transparece o desejo imperialista de alargamento da cultura alemã para fora dos "muros" das escolas teuto- brasileiras. Ele creditava que a obra do autor Büchler poderia servir a esse propósito.

De fato, com um simples e rápido olhar aos enunciados dos problemas propostos pelo autor, constatamos o quanto ele se esforçou para contextualizar sua obra, para inserir no texto de seus livros didáticos elementos do universo daqueles a quem tais livros se destinavam. Assim, trouxe para os enunciados dos problemas os mil réis, o tecido "chita" e os alimentos mais utilizados nas zonas coloniais como café, pêssegos, laranjas, batatas, leite, pão, vinho, arroz, açúcar e vinagre. Além disso, o segundo volume traz problemas envolvendo as dimensões de estados e rios brasileiros (Büchler, vol. 2, 1933, p. 17).

No prefácio à primeira edição do livro Pratischen Rechnenbuch, vol. 1, o autor dizia: “As diversas partes seguem um método rigoroso, evitando o desnecessário e dando à matéria uma tal disposição e forma, que tornará as lições de aritmética horas agradáveis aos mestres e professores” (Büchler, 1918, p. 4). Essa concepção de método rigoroso e de ensino prático que está no prefácio do livro revela a formação germânica do autor, os princípios seguidos pelos mestres de quem recebeu a orientação e cujo modelo seguiu. Para Bourdieu (2007, p. 206), os discípulos de uma determinada escola tendem a seguir o espírito moldado pela instituição: “[...] os espíritos assim modelados encontram-se predispostos a manter com seus 
pares uma relação de cumplicidade e comunicação imediatas".

No prólogo da terceira edição do primeiro volume e no prólogo do quarto volume da Aritmética Prática, Büchler deixou vestígios do método intuitivo (Correa e Eissler, 2017). Mas, em nossa opinião, foi sobretudo nos artigos que publicou no ALZ que estes estão mais explícitos. Embora o uso da memorização não esteja excluído da proposta metodológica deste autor. A tabuada de multiplicação (Figura 2) é apresentada na página 61, última do primeiro volume, mas não é acompanhada por nenhum texto que oriente seu uso. Como afirmam Valente e Pinheiro (2015, p. 23), as tabuadas não desapareceram depois do surgimento do método intuitivo.

[...] surge a necessidade de ruptura com a cultura de cantar a tabuada, como sinônimo de chegada de um novo tempo no ensino de matemática para os anos iniciais escolares. As tábuas, as tabuadas, no entanto, continuam presentes, como se mencionou, para levar adiante o novo ensino intuitivo. As novas tábuas de Pestalozzi vão ensejar a criação de outros dispositivos, outras tabuadas. É reforçada a ideia de que os primeiros passos para aprender a calcular ligam-se aos quadros, ao uso de dispositivos que possam referir-se à numeração.

Taboada de mulciphlicat.
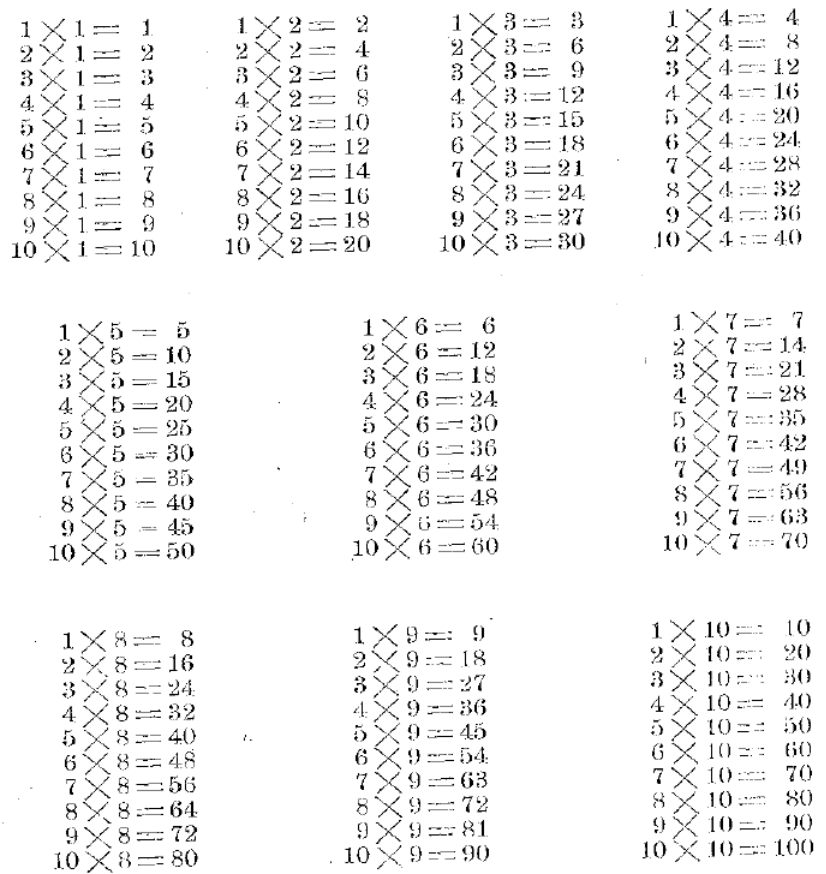

Figura 2: Tabuada de Multiplicação

Fonte: Büchler (1916, p. 61) 


\section{O Ensino da Aritmética segundo Otto Büchler}

O ALZ serviu a Büchler, também, para divulgar suas ideias sobre o ensino da aritmética. Em um de seus artigos, de 1914 - Contribuições para o Ensino da Aritmética [Beiträge für den Rechenunterricht] - é bastante visível a influência de Pestalozzi, aliás, o pedagogo mais citado no periódico no período em estudo.

Apresentaremos o artigo acima referido ${ }^{7}$ quase em sua íntegra, inserindo comentários, uma vez que ele traz, de maneira clara e objetiva, as proposições do autor sobre o ensino da matemática. O dividiremos em três categorias: ensino fundamental da aritmética, conceito de número e ensino de aritmética nas escolas multilíngues.

Sobre o ensino fundamental da aritmética, o autor aponta o que considera importante para o ensino dos números e diz como deve ser ministrado. Escolhe o conjunto ${ }^{8}$ de números de 1 até 10 como "[...] o mais importante campo numérico da aritmética, pois para que as crianças se tornem competentes em calcular, precisam antes de tudo ter “[...] compreensão, clareza e segurança nesse campo numérico” (Büchler, 1914, p. 5).

Para ele, o ensino deve ser gradual, sem pressa, pois as crianças, ao ingressarem na escola, possuem idade, talento e desenvolvimento mental bem diferentes. Assim ele recomenda aos professores certos cuidados, principalmente com aqueles que apresentam mais dificuldades com a aprendizagem da aritmética:

Se o professor quiser que também as crianças com menos talento progridam, por isso mesmo faz-se necessário que o progresso seja lento e tranquilo. Aqueles alunos que ficarem para trás, aqui, certamente não progredirão nas áreas seguintes, tornando-se um incômodo para o professor e para eles mesmos. Para reduzir a um número o menor possível essas crianças que ficam para trás (algumas sempre estarão), os resultados da aula não devem ficar gravados cedo demais na memória dessas crianças; é preciso deixar que sejam encontrados através do pensar e do calcular repetidamente (Büchler, 1914, p. 5 , grifos nossos).

Tendo ministrado aulas de Psicologia no DELS, Büchler já deveria conhecer, à época, a importância de estimular o interesse da criança, principalmente daqueles que pouco participavam das aulas. Assim afirmava: "É preciso estimular constantemente a vontade do mais fraco, elevar a confiança em si mesmo e despertar seu interesse. Poder-se-á perceber, assim, que algumas crianças que até então não participavam da aula aos poucos vão se interessando e se adaptando" (Büchler, 1914, p. 5, grifos nossos).

\footnotetext{
${ }^{7} \mathrm{O}$ artigo foi traduzido pela professora Flavia Sarreta.

${ }^{8} \mathrm{O}$ autor não usa a palavra conjunto numérico e sim campo numérico.
} 
A busca por desenvolver nas crianças uma percepção de segurança e clareza de conceitos, é apontada por Büchler como importante:

Tudo depende da base e da segurança com que as crianças calculam no campo numérico de 1-10 para que o progresso do passo seguinte esteja garantido. Por isso é melhor: segurança e clareza no campo numérico de 1-10 do que insegurança e capacidade fragmentada no campo numérico até 20 (Büchler, 1914, p. 5, grifos nossos).

Embora no primeiro ano escolar as crianças sejam introduzidas no conjunto numérico de 1 - 20, ele considerava como base o conjunto dos números de 1 até 10 , uma vez que, adquirindo segurança neste, estaria garantida a aprendizagem no conjunto maior até 20 . Assim repete: "Por isso é melhor: segurança e clareza no campo numérico de 1-10 do que insegurança e capacidade fragmentada no campo numérico até 20. É melhor: pouco e bem do que muito e mal" (Büchler, 1914, p. 5). Recomendava trabalhar no primeiro ano apenas a adição e subtração, considerando prematura a introdução das operações de multiplicação e divisão, que tornar-se-iam fragmentárias. Curiosamente, mais de cem anos após essa publicação, encontramos em livros didáticos russos para o ensino de matemática nos anos iniciais argumentações semelhantes dos autores, prescrevendo uma lenta apresentação dos números de 1 - 10 e a não ultrapassagem do conjunto dos números até 20 , bem como o trabalho com apenas as operações de adição e subtração para o primeiro ano escolar (Silva, 2017).

Praticamente, as mesmas ideias de Moro et al, por nós analisadas e publicadas em artigo intitulado Matemática para a primeira série em livros didáticos russos (Silva, 2017), são manifestadas e repetidas por Büchler (1914, p. 6) no AZL.

Diga-se mais uma vez que da clara compreensão e da segurança nesse conjunto numérico depende o progresso nos conjuntos numéricos seguintes. Por isso - e eu me dirijo especialmente aos colegas mais jovens e menos experientes, que lidam principalmente com os iniciantes - tenham paciência, muita paciência; tornem as aulas animadas através de visualização, clareza, torne a aula interessante, instigue os pequenos a pensar, à autodescoberta!

Instigar o pensamento e promover ações que permitam ao aluno descobrir conceitos e resultados é uma tônica no discurso de Büchler. Além disso, a recomendação da visualização remete a uma orientação do método intuitivo no ensino da matemática.

Como um claro seguidor de Pestalozzi, ele inicia uma abordagem mais aprofundada sobre o conceito de número citando o pensador suíço: "Visualização é o fundamento absoluto de todo conhecimento" (Büchler, 1914, p. 6).

A utilização de material concreto como um meio para auxiliar os alunos na 
compreensão de conceitos básicos da aritmética é proposta claramente:

Os conceitos de número surgem no espírito da criança pela visão e pelo contar de coisas concretas. Muitas crianças sabem contar até 10 quando ingressam na escola, muitas vezes até 20 e até mesmo 100; (os pais se divertem e se alegram de 'ensinar' isso aos filhos), mas esse contar das crianças não passa de um recitar mecânico dos números em sua sequência natural. Para lhes proporcionar o verdadeiro conhecimento do número, ou melhor dizendo, do conceito de número, é necessário que a criança entenda cada número como uma 'unidade' por si só e como uma soma de unidades, como uma multiplicidade. O número 2, por exemplo, deve ser visto como unidade 'dois' e como multiplicidade de 'um mais um'; o número 3, como 'três', como 1+1+1 e 2+1 (Büchler, 1914, p. 5).

A fim de esclarecer melhor como proceder, ele sugere o uso de objetos diversificados e de cores diferentes nas aulas iniciais, para que as crianças os manuseiem:

Transmite-se a ideia do número muito melhor e com mais segurança com objetos simples, que são de igual tamanho, material e cor, do que através de objetos artificiais ou através de figuras, que só distraem a atenção das crianças para o que não é essencial (Büchler, 1914, p. 5).

Chama a atenção para que o professor use objetos familiares às crianças e ao campo de visualização delas, como pauzinhos, feijões, panos, contas, etc. Previne que não só o professor deve mostrar esses objetos mas, principalmente, que as crianças devem manuseá-los. Quanto mais diversificados forem, diz ele, maior será a chance de compreensão dos conceitos. Um ensino ativo é recomendado, aproximando-se do divulgado em outros artigos publicados em periódicos pedagógicos no País.

A recomendação de materiais didáticos para o uso em sala de aula já aparecia fortemente nos Seminários Alemães de Formação de Professores no século XIX. O Brasil não estava alheio aos progressos ocorridos no campo educacional em outros países, devido a processos de transferência cultural, em que a circulação de ideias e de artefatos pedagógicos ocorria por vários meios. O papel de agentes culturais, dos intercâmbios entre países, quer seja por meio de encontros, exposições, livros de divulgação e viagens de estudos, serviu para disseminar ferramentas de ensino. As vagas pedagógicas como o método ativo e escola nova contribuíram para chamar a atenção sobre o importante papel da visualização no ensino, do uso de materiais didáticos colocados nas mãos dos alunos para que este, no ensino fundamental, pudesse fugir de um ensino essencialmente teórico.

Um material didático fortemente recomendado para o ensino da aritmética era o ábaco. Mas ele não explica como utilizá-lo nesse artigo. Apenas propõe três etapas para a formação do conceito de número, em que os objetos utilizados para a contagem são substituídos pelo ábaco e, após, esse é substituído pelo conceito de número puro. São elas:

$1^{\text {a }}$ etapa) "O ábaco vai para o primeiro plano enquanto os demais meios de visualização 
são eliminados aos poucos" (Büchler, 1914, p. 5).

$2^{\mathrm{a}}$ etapa: "O ábaco vai para o segundo plano e só reaparece se for realmente necessário. A denominação mexer com as contas, por enquanto, ainda é mantida" (Büchler, 1914, p. 5).

$3^{\text {a }}$ etapa: "Todos os meios de visualização são eliminados e trabalha-se apenas com os números puros (nus)" (Büchler, 1914, p. 6).

Seriam de Büchler essas ideias expressas com tanta veemência? O mais próximo de tal sequenciação foi encontrado em Calkins (1950) num capítulo em que ele introduz "lições para desenvolver as ideias elementares de número", sugerindo o uso de objetos além do “contador” (ábaco). É um contar com objetos e nele está incluído o ábaco. Após esse contar com objetos, sugere a introdução dos algarismos como símbolos dos números: "Sabendo as crianças contar, sem vacilação, de um a nove inclusive, ensinem-se-lhes os algarismos de 0 a 9 como símbolos dos números, ou sinais do número de coisas contadas" (Calkins, 1950, p. 254).

Embora as propostas sejam semelhantes, elas diferem, pois, para Büchler, após a introdução dos números "puros", é recomendável eliminar o uso de contagem por objetos, enquanto que, para Calkins, o trabalho com as representações dos números ainda pode ser acompanhado da visualização.

Para desenvolver o conceito de dezena, o autor salienta que: “[...] O número 10 ainda pode ser muito bem visualizado através de 10 dedos, 10 pauzinhos; são agrupados aos olhos das crianças em grupos de dez" (Büchler, 1914, p. 6, grifos do autor). Entretanto, considerava muito apropriado o uso do ábaco russo:

Nos conjuntos numéricos até 20 e 100, o ábaco russo presta um ótimo serviço; os 'feixes de dez' acima mencionados também se prestam a dividir um deles em 10 palitos. Facilmente as crianças passam a compreender que 10 unidades $=1$ dezena; 10 dezenas $=$ 1 centena e vice-versa, que 1 centena $=10$ dezenas e 1 dezena são 10 unidades. Os conceitos numéricos acima de 100 não são tão facilmente visualizáveis. Todavia, as crianças devem ser incentivadas em sua capacidade de formação de conceitos para que não precisem mais de meios de visualização (Büchler, 1914, p. 6).

Como o DELS era destinado, principalmente, às escolas étnicas e de confissão religiosa evangélica, o artigo de Büchler traz orientações metodológicas especialmente dedicadas aos professores de tais escolas. Esse é o objeto da próxima categoria analisada.

Entre os preceitos que julga importantes no ensino da aritmética e que podem promover a autonomia dos alunos encontram-se os seguintes: simplificação conveniente da matéria de aritmética, introdução de visualizações nos exercícios de aritmética, agrupamento das atividades e aplicações. Conhecendo a realidade das escolas étnicas e valorizando muito a 
compreensão da língua de conversação para a aprendizagem da aritmética, ele incluiu, em seu artigo, sugestões aos professores, as quais apresentaremos a seguir agrupadas por temática. As duas primeiras sugestões explicitam a visualização e a denominação:

Principalmente nos primeiros anos, a apresentação oral deve estar sempre atrelada à visualização objetiva [Sachanschauung], mais precisamente com coisas corporais, que as crianças não apenas 'veem', mas que também podem pegar na mão, 'tocar'. Os nomes das coisas utilizadas para a visualização somente serão ditas após o pedido: 'Dê nome a isto!' e com o artigo definido; por exemplo: a caneta, o dedo, a janela e não esta é a janela etc. Recomenda-se na primeira aula de alemão levar em consideração as necessidades da aula de aritmética, para que as denominações aqui necessárias sejam repetidas várias vezes (por ex. janela, mesa, banco, cadeira, bolinha, feijão etc.) (Büchler, 1914, out. p. 1).

As sugestões seguintes dizem respeito ao ensino de aritmética como uma maneira de fomentar a aprendizagem da língua materna. Os exemplos que dá, embora se refiram à aritmética, contemplam terminologia da geometria. Isso pode levar a suspeitar que breves noções geométricas tenham sido implementadas em tais escolas.

A aritmética ajuda, assim, a aula de alemão e toda aula de aritmética passa a ser uma aula para praticar a língua. Assim o professor de aritmética faz com que as crianças, ao executarem certas atividades, sempre falem em frases, por exemplo, Eu desenho um círculo, ele desenhou três bolinhas (pontos) etc. As chamadas 'palavras de função gramatical': ante, atrás, entre, e, menos, uma vez, através, também 'é' e 'são', entre outras, as crianças aprendem também na aula de aritmética a utilização em frases que estão relacionadas a uma ação (Büchler, 1914, out. p. 1).

A oralidade em sala de aula é estimulada com a seguinte sugestão: "O falar em voz alta e de modo estruturado, com ênfase clara nas consoantes finais deve também ser uma preocupação na aula de aritmética. Pensemos nas seguintes palavras: treze, trinta, quarenta e vinte e três etc" (Büchler, 1914, out. p. 1).

Conclui o artigo afirmando que o objetivo do ensino da aritmética é ensinar os alunos a pensar e a falar. Para tanto, o professor deve estimular as capacidades de observação, compreensão e aplicação. Finalmente, ele encerra dizendo: "Eles aprendem a julgar as relações numéricas e fatuais, a aplicar técnicas para calcular e assim vão adquirindo segurança e destreza mentais" (Büchler, 1914, out. p. 1).

Alemão, formado em escola alemã, Büchler não consegue escapar da sua cultura, que transparece em vários momentos de sua escrita, ao colocar em evidência, por exemplo, o sistema monetário alemão. Em artigo no AZL (Büchler, 1915), ao abordar operações aritméticas, traz como aplicações o câmbio e faz referência ao quarto volume de seu livro didático. Faz uma longa explanação da história e da importância do dinheiro como um meio 
de troca. O cálculo do câmbio, que, segundo ele, envolve moedas estrangeiras, é exemplificado tomando o marco alemão e a libra inglesa como moedas de troca. Os problemas envolvendo cerveja, bebida muito consumida na Alemanha, aparecem no volume 2 de seu livro didático, assim como problema que visa a calcular a extensão do Reino Alemão [Deutsche Reich] a partir de dados dos estados da Prússia, Bavária, Saxonia e Württenberg, como também o cálculo de populações de estados alemães. Alguns enunciados de problemas trazem dados sobre a história de reis e rainhas dos séculos XVIII e XIX dos reinados alemães (Büchler, $2^{\circ}$ vol., 1933, p. 26).

Tomando de empréstimo as conclusões de Bastos sobre as transferências culturais entre França e Brasil no período de 1870-1900, entendemos que houve também no contexto e período de nossa análise uma situação similar com "[...] influências na perspectiva de um imperialismo cultural, com o poder de universalizar os particularismos associados a uma tradição histórica singular, isto é, de uma realidade de capitalismo industrial, para uma sociedade escravocrata agrária-exportadora” (Bastos, 2000, p. 105).

\section{Concluindo ....}

Qualquer enquadramento rígido das ideias de Otto Büchler em propostas pedagógicas correntes no início do século XX seria precipitada e limitadora da abrangência que ele deixa transparecer em seus escritos. Ele estaria usando o método intuitivo, conforme propôs Pestalozzi e foi apropriado por Calkins? Limitar suas propostas de ensino da matemática exclusivamente ao método intuitivo também não parece totalmente adequado, uma vez que ele propôs um ensino ativo, com a participação da criança. Estaria ele se aproximando das ideias da Escola Nova? Se considerarmos como traços do escolanovismo a centralidade da criança nas relações de aprendizagem; o respeito às normas higiênicas na disciplina do corpo do aluno e de seus gestos, a cientificidade da escolarização de saberes e fazeres sociais; a exaltação do ato de observar, de intuir, na construção do conhecimento do aluno e a elaboração pela criança de seu próprio saber, podemos dizer que há indícios dele principalmente nas suas manifestações no ALZ e menos nos livros didáticos que escreveu. Esses indícios de elaboração pela criança do seu saber foram descritos no último item do presente artigo.

A proposta de ensino da aritmética por Otto Büchler veiculada, principalmente no ALZ, numa tentativa de conduzir os professores a uma leitura orientada de seus livros didáticos está 
permeada das interpretações que fez dos discursos de autores estrangeiros, a maioria europeus, à época preocupados com o ensino da matemática e, de maneira mais global, com a formação inicial das crianças.

Uma das motivações que nos instigam a pesquisar em História da Educação Matemática relaciona-se à constatação de que a releitura de textos não apenas nos permite entender como o conhecimento em um determinado contexto foi construído, mas, além disso, nos possibilita constatar uma contínua ressonância de propostas pedagógicas de mais de cem anos, nas vozes de autores modernos de livros didáticos. Büchler usou argumentos de clareza e compreensão na construção de conjuntos numéricos e os restringiu ao conjunto dos números naturais até vinte no primeiro ano de estudos. Como ele preconizava: "torne as aulas animadas através da visualização" e "instigue os pequenos a pensar, à autodescoberta". Isso está muito próximo, sabemos, das propostas atuais de um ensino desenvolvimental.

Não apenas agentes culturais, como Otto Büchler, foram responsáveis por transferências culturais. A investigação de Dittrich (2013) sobre o papel das Exposições Universais, eventos transnacionais iniciados na segunda metade do século XIX, mostra que por meio deles era possível aprender com o estrangeiro. Além disso, esses eventos permitiam um início de colaboração internacional. A partir de 1862 tais exposições ampliaram seu palco incluindo a educação. Outro exemplo de transferência cultural ocorreu quando o Brasil promoveu a Exposição Pedagógica de 1883, com a participação de representantes de países estrangeiros, entre eles a Alemanha.

Entretanto, no âmbito da investigação que deu origem a este artigo, identificamos dois vetores de transferências culturais: o agente Otto Büchler, numa atividade direta como professor do Seminário Alemão Evangélico de Formação de Professores para o Rio Grande do Sul, assim como seus escritos sobre matemática publicados nos livros didáticos e artigos divulgados no ALZ.

\section{Referências}

ALZ, Die Praktische rechenshule. Abr. 1915, p. 6.

ALZ, jan. 1923, p. 8-9.

ALZ, 1923, nov, p. 10.

ARENDT, I. C. (2008). Educação, Religião e Identidade Étnica: o Allgemeine Lehrerzeitung e a escola evangélica alemã no Rio Grande do Sul. São Leopoldo: Editora da Unisinos e Oikos. 
BASTOS, M. H. (2000). Ferdinand Buisson no Brasil - pistas, vestígios e sinais de suas ideias pedagógica (1870-1900). História da Educação. ASPHE/DAE/UFPEL, Pelotas, n. 8. 79-109.

BOURDIEU, P. (2007). A economia das trocas simbólicas. São Paulo: Perspectiva.

BÜCHLER, O. (1916). Praktische Rechenschule in vier Heften für Deutsche Schulen in Brasilien - 1 Heft. $2^{\text {a }}$ ed. São Leopoldo: Editora Rotermund.

BÜCHLER, O. (1933). Praktische Rechenschule in vier Heften für Deutsche Schulen in Brasilien - 2 Heft. 12a ed. São Leopoldo: Editora Rotermund.

BÜCHLER, O. (19??). Praktische Rechenschule in vier Heften für Deutsche Schulen in Brasilien -3 Heft. $9^{\text {a }}$ ed. São Leopoldo: Editora Rotermund.

BÜCHLER, O. (1917). Praktische Rechenschule in vier Heften für Deutsche Schulen in Brasilien -4 Heft. $2^{\text {a }}$ ed. São Leopoldo: Editora Rotermund.

BÜCHLER, O. (1918). Arithmetica Practica em quatro partes. IV. Parte. $3^{\text {a }}$ edição. São Leopoldo: Editora Rotermund.

BÜCHLER, O. (1914). Contribuições para o Ensino da Aritmética [Beiträge für den Rechenunterricht], ALZ, ago., 5-6.; out., p. 1.

BÜCHLER, O. (1915). Contribuições para o Ensino da Aritmética [Beiträge für den Rechenunterricht], ALZ, abr., 4-5.

BÜCHLER, O. (1917). Entusiasmo em nossa profissão [Begeisterung in unserm Beruf], ALZ, jul., p. 1, ago., p. 1.

CALKINS, N. A. (1950). Lições de Coisas. Trad. Rui Barbosa. Obras completas de Rui Barbosa v. XIII. 1886, Tomo I. MEC, Rio de Janeiro.

CERTEAU, M. (1982). A escrita da História. Rio de Janeiro; Editora Forense.

CORREA, R.; EISSLER, R. (2017). Cartas e postais como referência em problemas no livro de aritmética de Otto Büchler. Atos de Pesquisa em Educação. Cv. 12, n. 2, 389-405.

DITTRICHT, K. (2013). As exposições universais como mídias para a ação transnacional de saberes sobre o ensino primário na segunda metade do século 19. História da Educação, Porto Alegre v. 17, n. 41, Set./dez. 213-234.

EISSLER, R.; PINTO, N. B. (2013). A ideia de número na obra "Arithmetica Pratica em quatro partes" de Otto Büchler (1915): Contribuições ao ensino fundamental da matemática nos anos iniciais do ensino fundamental. In ANAIS DO XI ENEM: Educação e Perspectivas (pp. 1-17). Curitiba, 1-13.

ESPAGNE, M. (1999). Les transferts culturels franco-allemands. Paris: Presses Universitaires de France. 
FONTAINE, A. (2014). Pedagogia como transferência cultural no espaço franco-suíço: mediadores e reinterpretações de conhecimento (1850-1900). História da Educação, Porto Alegre, v. 18, n. 42, 187-207.

GAERTNER, R. (2004). A matemática escolar em Blumenau (SC) no período de 1889 a 1968: da Neue Deutsche Schule à Fundação Universidade Regional de Blumenau. (Tese de Doutorado em Educação Matemática). Universidade Estadual Paulista, Rio Claro.

HOFF, S.; CARDOSO, M. A. (2003). O Universal contido no manual O Ensino de Aritmética -1915. In: VI Seminário Nacional de Estudos e Pesquisas História, Sociedade e Educação no Brasil, 2003, Aracaju. A História da Escola pública no Brasil - Rede Histedbr. Aracaju: UFSE, v.1. 1-19.

KREUTZ, L. (1994). Material didático e currículo na escola teuto-brasileira. São Leopoldo: UNISINOS.

KUHN, M.; BAYER, A. (2016). Características das aritméticas da série Concórdia - Década de 1940. Perspectivas da Educação Matemática-INMA/UFMS v. 9, n. 21, 1131-1150.

KUHN, M.; BAYER, A. (2017). A prática da tabuada nas escolas paroquiais luteranas gaúchas do século XX. Revista Eletrônica de Educação. set./dez, v.11, n.3, 753-769.

LEXIS, W. (1904) Das Unterrischtswesen im Deutschen Reich. III Band [Das Volksschulwesen und das Lehrerbildungswesen]. Berlin: Asher \&Co.

MAURO, S. (2005). Uma história da matemática escolar desenvolvida por comunidades de origem alemã no Rio Grande do Sul no final do século XIX e início do século XX. (Tese de Doutorado em Educação Matemática). Universidade Estadual Paulista, Rio Claro.

NAUMANN, H. G. (1978) Discurso: 70 anos de formação de professores evangélicos no Rio Grande do Sul. Arquivo do IEI, 4 páginas.

SEYFERTH, G. (1982). Nacionalismo e identidade étnica: a ideologia germanista e o grupo étnico teuto-brasileiro numa comunidade do Vale do Itajaí. Florianópolis; Fundação Catarinense de Cultura.

SILVA, C. M. S. (2015) Transferências e apropriações de saberes: Friedrich Bieri e a matemática para o ensino primário. ). História da Educação, Porto Alegre, v. 19, n. 45, 43-66, jan./abr.

SILVA, C. M. S. (2016). Wilhelm Rotermund (1843-1925) vivendo em duas culturas. Rev. bras. hist. educ., Maringá-PR, v. 16, n. 4 (43), 94-122, out./dez.

SILVA, C. M. S. (2017). Matemática para a primeira série em livros didáticos russos. BOLETIM GEPEM, n. 71, 51-67, jul./dez.

VALENTE, W.; PINHEIRO, N. (2015). Chega de decorar a tabuada! - As Cartas de Parker e a Árvore do Cálculo na ruptura de uma tradição. Educação Matemática em Revista, Ano 16 , n. 16 , v. 1, 22-37. 
ISSN 1981-1322 DOI: http:// doi.org/105007/1981-1322.2019.e58617

Submetido em: 11/08/2018

Aceito em: 18/06/2019 